\title{
Factors Contributing to Posttraumatic Growth and Its Buffering Effect in Adult Children of Cancer Patients Undergoing Treatment
}

\author{
RICARDO J. TEIXEIRA, PhD and M. GRAÇA PEREIRA, PhD \\ School of Psychology, University of Minho, Braga, Portugal
}

\begin{abstract}
This study examined relationships among demographic, clinical, and psychosocial variables in adult children of cancer patients. Two bundred and fourteen participants completed measures of posttraumatic growth (PTG), distress, postraumatic stress disorder (PTSD) symptoms, social support, and family functioning. Significant gender differences in all PTG dimensions were found, as well as associations among PTG, gender, parental dependency, distress, PTSD, and family functioning. Social support was not a mediator in the relationship between gender and PTG. Gender, education, disease duration, dependency, distress, and family flexibility predicted PTG. Finally, PTG had a moderating effect in the relationship between distress and PTSD/social support. These results may guide psychosocial interventions in this population.
\end{abstract}

KEYWORDS posttraumatic growth, parental cancer, psychological distress, caregiving, chemotherapy

\section{INTRODUCTION}

Many studies have documented the negative secondary impact of cancer on family members, including heightened levels of psychological distress equal to or even greater than those of survivors (Gallagher, Parle, \& Cairns, 2002; Kim, Duberstein, Sörensen, \& Larson, 2005; Manne et al., 2004; T. Weiss, 2004a). Recent studies, however, have also shown that patients and their families can find benefit from the challenges associated with cancer (Moore

This study was financially supported by the Portuguese Foundation for Science and Technology (grant reference SFRH/BD/43275/2008).

Address correspondence to Ricardo J. Teixeira, School of Psychology, University of Minho, Campus de Gualtar, 4710-057 Braga, Portugal. E-mail: ricardojft@gmail.com 
et al., 2010; Zwahlen, Hagenbuch, Carley, Jenewein, \& Buchi, 2010). Family caregivers in oncology draw on diverse resources when confronting the stressors associated with illness, and a tendency toward action may contribute to posttraumatic growth (PTG) (Calhoun \& Tedeschi, 1998; Davis, Wohl, \& Verberg, 2007). Although most research has focused on the negative aspects of providing care in cancer settings, studies have increasingly begun to evaluate the perceived beneficial effects as well (Barakat, Alderfer, \& Kazak, 2006; Thornton \& Perez, 2006; T. Weiss, 2002; Wells, Cagle, Bradley, \& Barnes, 2008). PTG has been defined as a positive psychological change experienced as a result of the struggle with highly challenging life circumstances or traumatic events (Calhoun \& Tedeschi, 1999, 2008). As an individual attempts to incorporate the reality of a stressful event into current schemas, PTG may develop (Tedeschi \& Calhoun, 2004). PTG encompasses several domains, including greater appreciation for life, the development of meaningful interpersonal relationships, and a sense of greater personal strength (Tedeschi \& Calhoun, 2004). Individuals who develop PTG may have a renewed desire to reconnect with family members or may experience greater self-efficacy after having survived a traumatic event. PTG may be conceptualized as a process or an outcome (Tedeschi \& Calhoun, 2004). The development of PTG may occur several years after illness or injury onset and persist for long periods of time once it develops (Chun \& Lee, 2008; M. L. Wong, Cavanaugh, Macleamy, Sojourner-Nelson, \& Koopman, 2009). In the context of parental cancer, Leedham and Meyerowitz's (1999) study of beneficial findings is especially groundbreaking. The authors evaluated the benefits derived from experiences with cancer, and 93\% of the adult daughters sampled indicated that parental cancer had caused at least one positive change in their lives. The fact that the overwhelming majority of these respondents derived benefits from the experience of parental cancer suggested the need for research to analyze psychosocial consequences (positive and negative) as well as their predictors in this population. Some comparative research reports that the degree of PTG is quite similar between women with breast cancer and their daughters (Cordova, 2008; Sears, Stanton, \& DanoffBurg, 2003). One of the most important studies in this field, conducted by Mosher, Danoff-Burg, and Brunker (2006), evaluates the predictors of PTG in adult daughters of patients with breast cancer, such as coping strategies and caregiving. In this research, personal characteristics (age, income, education, marital status, optimism) were not correlated with PTG, although a better perception of cancer-related stress and a greater level of social support have proved to promote this type of growth. These results refine Calhoun and Tedeschi's (2008) model, which identifies a strong stressor engagement in the context of high social support, as a factor promoting PTG. Also consistent with this model is the discovery that the active management of emotions and stressors associated with parental cancer stimulates greater PTG. Such PTG includes greater development of the approach-oriented coping strategies, 
active coping, social support seeking, and emotional processing (Mosher et al., 2006).

\section{Sociodemographic Variables Related to PTG}

Various studies have examined sociodemographic variables that are believed to influence the emergence of PTG. For example, research supports that minority population members are more likely to perceive benefit and meaning from a traumatic event (Helgeson, Reynolds, \& Tomich, 2006). The literature also suggests that cultural differences may play a role in the expression of PTG patterns, especially at the level of spiritual change (Morris, ShakespeareFinch, Rieck, \& Newbery, 2005; Shakespeare-Finch, Smith, Gow, Embleton, $\&$ Baird, 2003). Age and gender have also been strongly implied to influence the emergence of PTG (Vishnevsky, Cann, Calhoun, Tedeschi, \& Demakis, 2010). Studies reveal that higher levels of PTG have been reported among younger adults (Bower et al., 2005; Cordova et al., 2007; Lechner et al., 2003; Widows, Jacobsen, Booth-Jones, \& Fields, 2005), and mostly among women (Curbow, Legro, Baker, Wingard, \& Somerfield, 1993; Linley \& Joseph, 2004; Park, Cohen, \& Murch, 1996; Tedeschi \& Calhoun, 1996; Widows et al., 2005), a finding that is in accordance with research on gender and coping. It seems that women tend to employ more positive reappraisal and positive self-talk than men (Park et al., 1996; Tamres, Janicki, \& Helgeson, 2002), despite their experience of greater stress in response to adversity (Anderson \& Manuel, 1994; Rausch, Auerbach, \& Gramling, 2008). Education and employment have also been associated with increased PTG. For example, one study (Russell, White, \& White, 2006) indicated that verbal skills and reading stimulate the formulation of existential questions (as well as the search for their answers), and that employment can provide people with meaningful and productive roles as well as coping skills in the face of adversity. However, another study (Widows et al., 2005) indicates a negative association between PTG and education. Finally, marital status is also a common predictor included in some PTG studies, however yielding mixed results (Rubin \& White-Means, 2009; Widows et al., 2005).

\section{Clinical Variables Related to PTG}

Several clinical cancer-related variables are salient in the literature about PTG. In fact, research shows the existence of a positive association between disease duration and levels of perceived positive change (Cordova, Cunningham, Carlson, \& Andrykowski, 2001; Klauer, Ferring, \& Filipp, 1998). However, in other studies no significant associations emerged (Bellizzi \& Blank, 2006; Mosher et al., 2006; Sears et al., 2003; T. Weiss, 2004b), or there was even a negative correlation (Fromm, Andrykowski, \& Hunt, 1996; T. Weiss, 2004b). Considering chemotherapy as an additional stressor for patients and 
their families, the duration of this treatment may also be an important promoter of PTG (Baider \& De-Nour, 1988; Schumacher, 1996). Caregiving duration is another important variable in cancer settings. According to Calhoun and Tedeschi (1998), a tendency toward action may contribute to PTG, and because caregivers draw on diverse resources when confronting the stressors associated with illness (Mosher et al., 2006), caregiving duration might prompt greater PTG. It is important to note that duration-related variables raise the question if there are differences in growth as a function of time (Prati \& Pietrantoni, 2009). Most approaches are centered on the hypothesis that growth takes place after an extended process of working through the experience (Andrykowski, Brady, \& Hunt, 1993; E. J. Taylor, 2000), although some studies support the opposite (Frazier, Conlon, \& Glaser, 2001). Another important clinical variable for cancer caregivers is the patient's level of dependence (Given, Given, Helms, Stommel, \& DeVoss, 1997; Given et al., 1993; Nijboer, Triemstra, Tempelaar, Sanderman, \& van den Bos, 1999; Toseland, Blanchard, \& McCallion, 1995). In a parental cancer context, although it can be argued that most adult children do not cohabit with their parents, this does not mean that the child-parent interdependent relationship is no longer present (Levesque \& Maybery, 2012). The literature is inconsistent on the association between PTG and parental dependency in cancer settings. However, because this variable may potentiate greater distress, one may assume its relationship with PTG.

\section{Psychosocial Variables Related to PTG}

Experiencing an event as more distressing may result in greater motivation to make meaning of traumatic events, which subsequently leads to a greater experience of PTG (Tedeschi \& Calhoun, 1995). Tedeschi and Calhoun $(1995,2004)$ assert that the experience of PTG does not necessarily imply the absence of distress and suggest that both can coexist as distinct constructs. Nevertheless, several studies have found an inverse association between measures of PTG and distress (Carver \& Antoni, 2004; Davis, NolenHoeksema, \& Larson, 1998; Frazier et al., 2001; Linley, Joseph, \& Goodfellow, 2008; J. C. McMillen, Smith, \& Fisher, 1997; Updegraff, Taylor, Kemeny, \& Wyatt, 2002). However, a great amount of research provides evidence for a positive relationship between PTG and psychological distress, especially when posttraumatic stress disorder (PTSD) is assessed (Morris et al., 2005; Taku, Cann, Calhoun, \& Tedeschi, 2008; Zoellner \& Maercker, 2006). Because positive and negative consequences can follow trauma, PTSD literature is thought to be a good place to look for new PTG correlates. One of these contexts is oncology (Cordova et al., 2007). For example, Barakat et al. (2006) demonstrated that, after controlling for other variables (i.e., age at diagnosis, life threat, and treatment intensity), PTSD remained significantly predictive of PTG in a sample of cancer survivors. In caregivers, this 
association is also prevalent (Mosher \& Danoff-Burg, 2005). In fact, the literature supports the existence of a curvilinear relationship between trauma severity and PTG (Fontana \& Rosenheck, 1998; Kleim \& Ehlers, 2009; Lechner et al., 2003; Schnurr, Rosenberg, \& Friedman, 1993), that is, PTG increases as PTSD severity increases. An interesting study exploring this relationship was carried out by Levine, Laufer, Hamama-Raz, Stein, and Solomon (2008). Using curvilinear modeling, the authors proved that the relationship took the shape of an inverted $U$, that is, individuals with mild or severe PTSD show lower levels of growth, whereas a moderate level of PTSD appears optimal for experiencing positive growth. Actually, trauma severity has not been analyzed in much detail within PTG research, although objective and subjective perceptions of stress severity have been found to be related to benefit finding (Helgeson et al., 2006; Morris et al., 2005). Surrounding a cancer diagnosis, generally, research supports the negative psychosocial adversity, with patients as well as their first-degree relatives exhibiting tremendous variability in psychological distress (Coyne, Benazon, Gaba, Calzone, \& Weber, 2000; Kash, Holland, Halper, \& Miller, 1992; Kornblith et al., 1990; Massie \& Holland, 1990; Moyer \& Salovey, 1996; Offit \& Brown, 1994; Thewes, Meiser, Tucker, \& Schnieden, 2003). Given these data, it is evident that the relationship between PTG and psychological distress is complex and further studies are necessary.

One prominent variable in PTG research is social support (J. C. McMillen et al., 1997; Schroevers, Helgeson, Sanderman, \& Ranchor, 2010; Schulz \& Mohamed, 2004), being a well-known predictor of positive change after a life crisis or trauma (Tedeschi \& Calhoun, 2004). By self-disclosing and seeking help from others, individuals discover positive aspects of the trauma of which they may not have been aware. In this context, a recent meta-analysis (Prati \& Pietrantoni, 2009) showed that social support promotes effective coping strategies, which in turn endorse positive outcomes. A relationship has been found between stress-related growth and satisfaction with one's social support system, suggesting that a good social support system is an important variable in the development of PTG (Park et al., 1996). Although trauma can lead to social withdrawal or attempts to avoid intimacy in our interpersonal lives, traumatic events such as losing a loved one can also lead to an increased sensitivity or empathy for others and increased appreciation for our social support system of family and friends (Collins, Taylor, \& Skokan, 1990; Lechner et al., 2003). For example, a recent study of parentally bereaved adolescents and young adults (Wolchik, Coxe, Tein, Sandler, \& Ayers, 2008) showed that seeking support was a significant predictor of PTG (Tedeschi \& Calhoun, 1996). For the caregiver population in oncology, this is also prevalent, as T. Weiss's (2002) study with husbands showed. In addition, Kim, Wellisch, Spiller, and Crammer (2007) reported that caregivers of a mixed group of cancer survivors were more likely to report benefit finding if they perceived a greater availability of social support. 
A variable not so explored in the PTG literature is family functioning. For the past two decades, in a paradigmatic shift, the focus in the family literature moved from viewing families' functioning through a deficit-based lens to a strength-based perspective (Hawley \& DeHaan, 1996; Walsh, 2003). Families' resilience and ability to thrive in the aftermath of the struggle with adversity has been mostly examined from the perspective of family stress and coping (Patterson, 2002). Families can respond to a traumatic event with PTG. According to complexity theory (Warren, Franklin, \& Streeter, 1998), severe events have the potential to set off second-order change processes that produce fundamental shifts in systems and lead to a higher level of functioning rather than to homeostasis. Family PTG represents an application of this general principle of the family system. For example, facing cancer, a family functioning appears to change over the course of the illness and treatment, and the influence of family functioning on individual members' adjustment seems to depend on the demands of the stage of illness/treatment (Barakat \& Kazak, 1999). In fact, empirical studies about PTG in caregiving oncological contexts have been done mostly on the individual level. However, two exceptions are the studies by T. Weiss (2004a, 2004b) and Manne et al. (2004), which looked at growth in couples related to the encounter with breast cancer. T. Weiss (2004a, 2004b) describes a woman with breast cancer and her partner as a system coping with trauma because they report PTG and survivor's growth that are significant predictors of partner's growth. Manne et al. (2004), in a longitudinal study, found that women's and partners' growth over time were positively correlated, and women's growth increased when their partners were emotionally expressive.

Based on previous research, this study analyzed the following hypotheses: (1) Social support acts as mediator in the relationship between gender and PTG; (2) There is a quadratic relationship between PTSD and PTG; (3) Demographic, clinical, and psychological variables will predict PTG; (4) PTG has a moderating effect between distress and PTSD, and between distress and social support. This effect will be examined by considering different stressors associated with parental cancer taking elapsed time in consideration.

\section{METHOD}

\section{Participants and Procedures}

The sample consisted of 214 adult children of patients undergoing chemotherapy (all White). The sociodemographic and clinical data collected about parents was completed by their adult children. Of these adult children, 74\% were women, with a mean age of 33.1 years $(S D=9.1$; range = 18-61 years); 47\% had a partner; and 63\% had less than a high school education. Concerning clinical information, $60 \%$ registered the disease duration of the parent as less than one year, 69\% noted that the parent was on 
chemotherapy for less than one year, and only 39\% provided care for more than a year. Only 21\% of adult children perceived the parent in treatment as completely reliant on their caregiving. Of the parents, 57\% were female, with an average age of 62.1 years $(S D=9.2$; range $=42-85$ years , and $78 \%$ were married. $60 \%$ of parents had cancer of the digestive system, $21 \%$ of the reproductive system, $7 \%$ in the respiratory system, and $12 \%$ in other areas.

This is a cross-sectional study, with a research design approved by the Ethics Committees of three general hospitals in northern Portugal. Participants were adult children who, during the period of data collection, accompanied the parent diagnosed with cancer to chemotherapy. This was a convenience sample with voluntary participation. Inclusion criteria required that participants be age $\geq 18$ years, have a parent (or both) in chemotherapy, accompany the parent to the hospital for treatment (minimum criterion for defining the adult children as "caregiver"), and not suffer from oncological, psychiatric, or neurological disease. All participants were invited to participate in the study, informed about its purpose, and were assured of anonymity and confidentiality.

\section{Measures}

Postraumatic Growth Inventory. The Portuguese version of the 21item Posttraumatic Growth Inventory (PTGI) (Teixeira \& Pereira, in press a; Tedeschi \& Calhoun, 1996) was used. Self-responses are organized on a 6-point scale (0-5), with higher values corresponding to greater PTG. Participants were asked to focus on the experience of caregiving for their parent with cancer. Pearson correlations between the subscales and the total score were high $(p<.001)$, and Cronbach's alphas were .85, .84, .87, .69, and .62 for the new possibilities, personal strength, relating to others, spiritual growth, and appreciation of life subscales, respectively. Internal consistency of the global scale was .94.

Depression Anxiety Stress Scales. The Portuguese version of the Depression Anxiety Stress Scales (DASS-21) was used (Lovibond \& Lovibond, 1995; Pais-Ribeiro, Honrado, \& Leal, 2004). This is a 21-item scale that includes three subscales: depression, anxiety, and stress. The DASS-21 employs a 4-point scale (0-3), with higher scores indicating greater negative affective states. In this sample, Cronbach's alphas were suitable: total scale "distress" ( $\alpha=.94)$, depression $(\alpha=.89)$, anxiety $(\alpha=.82)$, and stress $(\alpha=.87)$.

Impact of Event Scale-Revised. The 22-item Portuguese version of the Impact of Event Scale-Revised (IES-R) (Pereira \& Teixeira, 2011; D. Weiss \& Marmar, 1997) was used. This is a measure of current subjective distress for a specific traumatic event. Respondents are asked to rate on a 5-point scale (0-4) how distressing symptoms of avoidance, hyperarousal, and intrusion 
have been in the past 7 days. In this sample, Cronbach's alphas were .93 for hyperarousal, .74 for intrusion, .70 for avoidance, and .93 for the total scale. A cutoff of 33 was used for a probable diagnosis of PTSD (Creamer, Bell, \& Failla, 2003; Wang et al., 2011).

Satisfaction with Social Support Scale. The Portuguese 15-item Satisfaction with Social Support Scale (SSSS) (Pais-Ribeiro, 1999) was used, a measure of perceived social support for healthy and clinical populations (Santos, Pais-Ribeiro, \& Lopes, 2003). Self-responses are organized on a 5-point scale (1-5). Higher values correspond to a perception of greater satisfaction with social support. The SSSS subscales showed satisfactory internal consistency in this sample: satisfaction with friendships $(\alpha=.81)$, intimacy $(\alpha=.63)$, satisfaction with family $(\alpha=.87)$, social activities $(\alpha=.70)$. Cronbach's alpha for the total scale was .85 .

Family Adaptability and Cobesion Evaluation Scales. The Portuguese version of Family Adaptability and Cohesion Evaluation Scales-Fourth Version (FACES-IV) (Olson, 2011; Pereira \& Teixeira, in press) was used, a selfreport measure that assesses family functioning according to the circumplex model of marital and family systems. The two primary dimensions measured are cohesion and flexibility. It comprises 42 items on a Likert-type scale divided into six scales: two balanced scales (cohesion and flexibility) assessing central-moderate areas, and four unbalanced scales (enmeshed, disengaged, rigid, and chaotic) assessing the lower and the upper ends of cohesion and flexibility (Olson, Gorall, \& Tiesel, 2006a). The central hypothesis of the circumplex model is that healthy families are more balanced, whereas problematic families are more unbalanced (Olson, 2011). For the purposes of this study, only the FACES-IV balanced scales were used, showing good internal consistency: balanced cohesion $(\alpha=.83)$ and balanced flexibility $(\alpha=.70)$.

Family Communication Scale. The Family Communication Scale (FCS) (Olson \& Barnes, 2004) was used, a 10-item Likert-type measure based on the 20-item Parent-Adolescent Communication Scale (PAC) (Barnes \& Olson, 1985). The FCS can be used with a variety of family forms at various lifecycle stages related to the circumplex model. Family communication is defined as the systemic capacity for positive communication within marital or family systems and is seen as a facilitator that can change the levels of cohesion and flexibility (Olson, Gorall, \& Tiesel, 2006b). In this sample (Pereira \& Teixeira, in press), the internal consistency was .89.

Family Satisfaction Scale. The Family Satisfaction Scale (FSS) (Olson, 2004) was used, a 10-item Likert-type scale based on the original 14-item, to assess the degree of satisfaction with aspects related to family cohesion and flexibility. Family satisfaction is defined as the degree to which family members feel happy with and fulfilled by each other. Higher scores on this scale indicate that members are happy with their family (Olson et al., 2006b). In this sample (Pereira \& Teixeira, in press), the internal consistency was .93. 


\section{Data Analysis}

Descriptive statistics were obtained after ensuring that all variables followed normal distribution. Pearson correlation was used to test the association between PTG, demographic, clinical, and psychosocial variables. Point biserial correlation was chosen for the dichotomous nominal variables. To assess the importance of gender on PTG dimensions, a MANOVA was performed, and for global PTG, the ANOVA. To calculate the mediation effect of social support, multiple regressions were used employing causal steps methodology (Baron \& Kenny, 1986; Preacher, Rucker, \& Hayes, 2007). Comparative analysis regarding gender differences in PTSD severity was performed with chi-square, and $t$ tests were used to analyze differences in PTSD versus non-PTSD groups in terms of PTG dimensions. To examine the relationship between PTSD severity and PTG, curvilinear modeling was conducted. The predictors of PTG were studied using hierarchical regression analysis (Enter method). Finally, analyses of moderating effects were performed using multiple hierarchical linear regressions (Aiken \& West, 1991; Baron \& Kenny, 1986). Post hoc simple slope analyses were conducted to determine the nature of the significant interaction among continuous variables found in the primary analysis (Curran, Bauer, \& Willoughby, 2004), using the mean and one $S D$ above/below the mean defining high/low moderators (Aiken \& West, 1991).

\section{RESULTS}

\section{Descriptive Results}

Analyses were conducted to examine relationships among PTG and demographic, clinical, and psychological variables in the sample of adult children caregivers. As shown in Table 1, there were significant relationships between PTG and gender $(p<.05)$, level of dependency $(p<.01)$, distress $(p$ $<.01)$, PTSD symptoms $(p<.01)$, family cohesion $(p<.01)$, family flexibility $(p<.01)$, and family communication $(p<.05)$. In turn, PTG was not significantly related to age, income, education, marital status, disease duration, chemotherapy duration, caregiving duration, or even social support or family satisfaction (all $p s<.05$ ).

As shown in Table 2, the mean PTGI total score for the all sample was 58 $(S D=22$; possible range: 0-105). Concerning gender comparison, women reported significantly higher levels of PTG in all the PTGI dimensions, as well as for the total score, at $p<.05$ level.

Research indicates that the value of 33 points in the IES-R represents the best cutoff for a probable diagnosis of PTSD (Creamer et al., 2003; Wang et al., 2011). In this sample, this value allocated 86 possible PTSD cases. This 86 participants revealed significant higher levels of overall PTG 


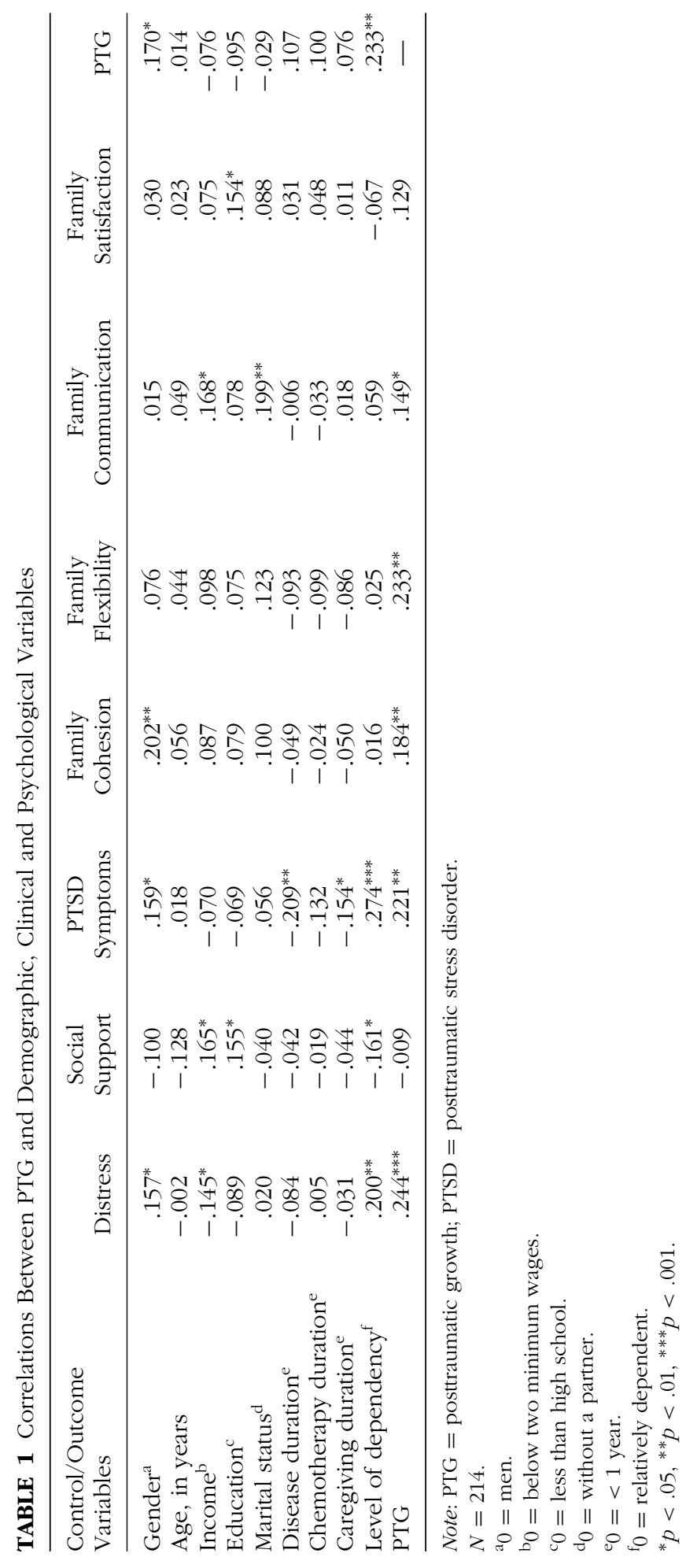




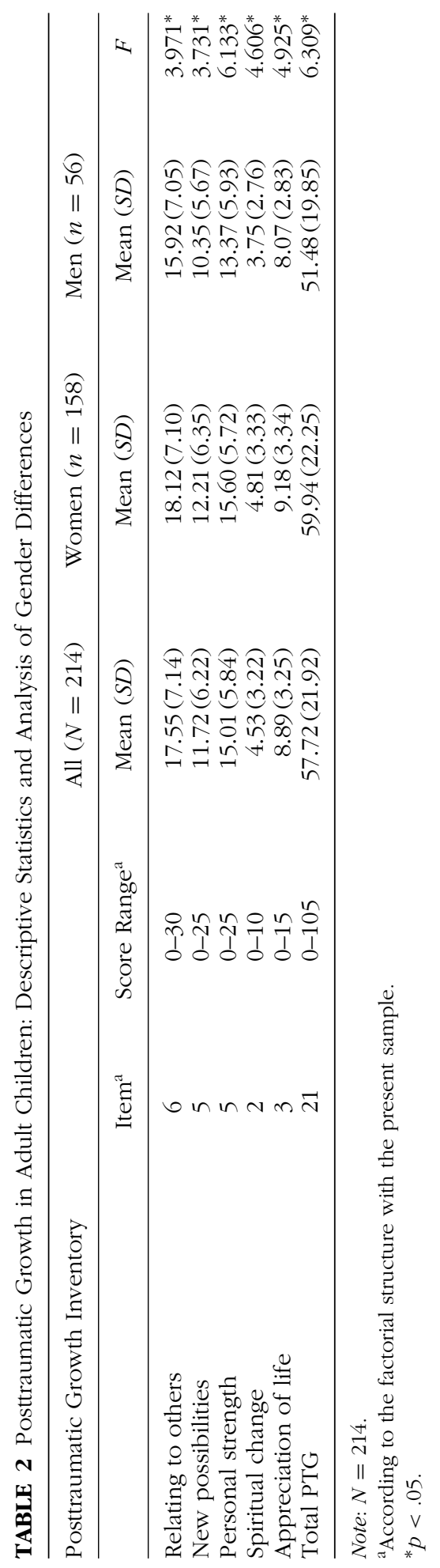


$(M=61.33, S D=23.4)$ when compared with participants below the cutoff $(M=55.30, S D=20.88) t(212)=-1.987, p<.05$. More specifically, these differences were prevalent for relating to others, $t(212)=-2.420, p<.05$, and new possibilities, $t(212)=-2.084, p<.05$, dimensions, but not significant for spiritual change, $t(212)=-1.642, p=.102$, appreciation of life, $t(212)$ $=-.910, p=.364$, or personal strength, $t(212)=-.867, p=.387$. A further gender comparative analysis, $\chi^{2}(1)=4.257, p<.05$, odds ratio $(\mathrm{OR})=$ 2.0 ; sensibility $=40 \%$, specificity $=60 \%$, revealed that women $(44 \%$ with probable PTSD) reported higher PTSD symptoms severity than men (29\% with probable PTSD).

\section{Mediating Effect of Social Support}

The first hypothesis was based on the results of a study carried out by Swickert and Hittner (2009) that showed social support to act as a mediator in the relationship between gender and PTG. However, the mediation model proposed was not borne out because there was a nonsignificant association between gender and social support. Using total SSSS scores, results were higher in men $(M=58.16, S D=9.24)$ than in women $(M=55.94, S D=$ 9.90), although this difference was not significant, $F(1,212)=2.144, p=.15$.

\section{Relationship Between PTSD Symptoms and PTG}

The purpose of the second hypothesis was to further examine the relationship between PTSD severity and PTG in this sample. In accordance with previous findings by Levine et al. (2008), curvilinear modeling was conducted. Results showed a significant linear effect of PTSD severity on growth $\left(\beta=.221, R^{2}=.049, p<.01\right)$, and not a quadratic effect $\left(\beta=.129, R^{2}=\right.$ $.050, p=.586)$.

\section{Predictors of PTG}

The third hypothesis was based on existing literature regarding predictors of PTG. A multiple regression model was performed with the following predictors: gender, age, income, education, and marital status in Step 1 as control variables; disease duration, duration of chemotherapy, duration of caregiving, and level of dependency were entered in Step 2; distress, PTSD symptoms, social support and family flexibility were entered in Step 3. The analysis yielded a significant overall model, $F(13,189)=4.050, p<.001$. Predictors were significant, accounting for $22 \%$ of the variance in PTG. As shown in Table 3, age, income, and marital status were not associated with high PTG, and neither was treatment and caregiving duration or, in terms 
TABLE 3 Hierarchical Multiple Regression Analysis Results for Predictors of Posttraumatic Growth (final model)

\begin{tabular}{|c|c|c|c|}
\hline Predictors & $b$ & $\mathrm{SE} b$ & $\beta$ \\
\hline \multicolumn{4}{|l|}{ Step 1} \\
\hline Gender ${ }^{\mathrm{a}}$ & 6.784 & 3.352 & $.136^{*}$ \\
\hline Age & -.036 & .189 & -.015 \\
\hline Income $^{b}$ & .339 & 3.403 & .007 \\
\hline Education $^{\mathrm{c}}$ & -7.157 & 3.467 & $-.158^{*}$ \\
\hline Marital status $^{\mathrm{d}}$ & -5.043 & 3.637 & -.115 \\
\hline \multicolumn{4}{|l|}{ Step 2} \\
\hline Disease duration $^{\mathrm{e}}$ & 14.090 & 6.645 & $.316^{*}$ \\
\hline Chemotherapy duration ${ }^{e}$ & 4.465 & 5.216 & .095 \\
\hline Caregiving duration ${ }^{\mathrm{e}}$ & -11.974 & 6.655 & -.267 \\
\hline Level of dependency ${ }^{f}$ & 9.851 & 3.838 & $.183^{*}$ \\
\hline \multicolumn{4}{|l|}{ Step 3} \\
\hline Distress & .166 & .084 & $.178^{*}$ \\
\hline Posttraumatic stress disorder symptoms & .592 & .921 & .058 \\
\hline Social support & .145 & .163 & .064 \\
\hline Family flexibility & .321 & .092 & $.240^{* *}$ \\
\hline
\end{tabular}

Note: $\mathrm{N}=214 . R^{2}=.047$ for Step $1, p=.089 ; \Delta R^{2}=.070$ for Step $2, p<.01 ; \Delta R^{2}=.101$ for Step $3, p$ $<.001 ; R^{2}=.218$, Adjusted $R^{2}=.164$.

${ }^{\mathrm{a}} 0=$ male, $1=$ female.

$\mathrm{b}_{0}=$ below two minimum wages, $1=$ above two minimum wages.

$\mathrm{c}_{0}=$ less than high school, $1=$ more than high school.

${ }^{\mathrm{d}} 0=$ without a partner, $1=$ with a partner.

$\mathrm{e}_{0} \leq 1$ year, $1 \geq 1$ year.

${ }_{\mathrm{f}} 0=$ relatively dependent parent, $1=$ dependent parent.

${ }^{*} p<.05,{ }^{* *} p<.01$.

of psychosocial variables, PTSD symptoms, and social support. However, the regression model revealed that gender $(\beta=.136, p<.05)$, education $(\beta=-.158, p<.05)$, disease duration $(\beta=.316, p<.05)$, and level of dependency $(\beta=.183, p<.05)$ were significantly associated with increased PTG. When these demographic and clinical predictors were controlled, psychosocial variables explained an additional $10 \%$ of the variance, with only distress $(\beta=.178, p<.05)$ and family flexibility $(\beta=.240, p<.01)$ emerging as significant predictors.

\section{Analysis of Moderating Effects}

To test the last hypothesis, regarding PTG as a moderator in the relationship between distress and other psychosocial variables (PTSD symptoms, and social support), several multiple hierarchical linear regression equations were conducted, one for each major stressor (below and above 1 year, in each outcome variable) (Aiken \& West, 1991; Baron \& Kenny, 1986). As shown in Table 4, when considering PTSD symptoms as the outcome, only the interaction term between distress and PTG in the group that provided care 
TABLE 4 Multiple Regression Analyses of Distress, Posttraumatic Growth (PTG), and Distress by PTG Interactions, for Each Major Stressor Temporal Group (standardized $\beta \mathrm{s}$ )

\begin{tabular}{|c|c|c|c|c|}
\hline & \multicolumn{2}{|c|}{ PTSD symptoms } & \multicolumn{2}{|c|}{ Social Support } \\
\hline & $<1$ year & $>1$ year & $<1$ year & $>1$ year \\
\hline \multicolumn{5}{|l|}{ Stressor: Disease duration ${ }^{a}$} \\
\hline Distress & $.665^{* * *}$ & $.548^{* * *}$ & $-.356^{* * *}$ & $-.455^{* * *}$ \\
\hline PTG & -.040 & $.347^{* * *}$ & .037 & $.222^{*}$ \\
\hline Distress $\times$ PTG interaction & .115 & .142 & 142 & $.244^{*}$ \\
\hline Adjusted $R^{2}$ & 447 & .519 & 107 & 171 \\
\hline$\Delta R^{2}$ & .013 & .018 & .020 & .052 \\
\hline Stressor: Caregiving duration ${ }^{a}$ & $<1$ year & $>1$ year & $<1$ year & $>1$ year \\
\hline Distress & $.656^{* * *}$ & $.611^{* * *}$ & $-.352^{* * *}$ & $-.421^{* * *}$ \\
\hline PTG & -.062 & $.322^{* * *}$ & .000 & $.268^{*}$ \\
\hline Distress $\times$ PTG interaction & $.135^{*}$ & .095 & 136 & $.258^{*}$ \\
\hline Adjusted $R^{2}$ & .440 & .544 & 108 & .171 \\
\hline$\Delta R^{2}$ & .018 & .008 & .018 & .059 \\
\hline Stressor: Chemotherapy duration ${ }^{\mathrm{a}}$ & $<1$ year & $>1$ year & $<1$ year & $>1$ year \\
\hline Distress & $.648^{* * *}$ & $.631^{* * *}$ & $-.387^{* * *}$ & $-.369^{* *}$ \\
\hline PTG & .017 & $.266^{* *}$ & .062 & .175 \\
\hline Distress $\times$ PTG interaction & 107 & .074 & .140 & $.241^{*}$ \\
\hline Adjusted $R^{2}$ & .444 & .503 & .124 & .121 \\
\hline$\Delta R^{2}$ & .011 & .005 & .019 & .053 \\
\hline
\end{tabular}

Note: $N=214$

${ }^{\mathrm{a}}$ Number of participants per major stressor controlling time variable: Disease duration $(<1$ year, $n=128$; $>1$ year, $n=86$ ), Caregiving duration ( $<1$ year, $n=129$; $>1$ year, $n=82)$, Chemotherapy duration $(<1$ year, $n=147 ;>1$ year, $n=67)$.

${ }^{*} p<.05,{ }^{* *} p<.01,{ }^{* * *} p<.001$.

for less than a year explained significant increases in variance, $\Delta R^{2}=.018$, $F(3,125)=34.529, p<.05$. In turn, when considering social support as the outcome, all the interaction terms between distress and PTG in stressors over a year explained significant increases in variance: disease duration, $\Delta R^{2}=$ $.052, F(3,82)=6.862, p<.05$, caregiving duration, $\Delta R^{2}=.059, F(3,78)=$ $6.575, p<.05$, and treatment duration, $\Delta R^{2}=.053, F(3,63)=4.015, p<.05$.

Post hoc simple slope analyses (Curran et al., 2004) were conducted to determine the nature of the significant interaction among continuous variables found in the primary analysis (see Figure 1). The plots of the interaction and post-hoc analyses of the simple slopes indicate that for stressors below a year (caregiving duration), only under the condition of high PTG there is a significant positive linear relationship between distress and PTSD symptoms. For stressor's duration above a year (disease, caregiving, and chemotherapy durations), when PTG is high, there is a positive significant relationship between distress and social support (for chemotherapy duration, there is only a marginal significance; $p=.06$ ). Additionally, when PTG is low, the linear relationship becomes negative and also significant. However, interestingly, it is stronger for lower levels of PTG: $t=-2.45, p<.05 ; t=-2.53, p<.05$; and $t=-2.07, p<.05$, respectively. 

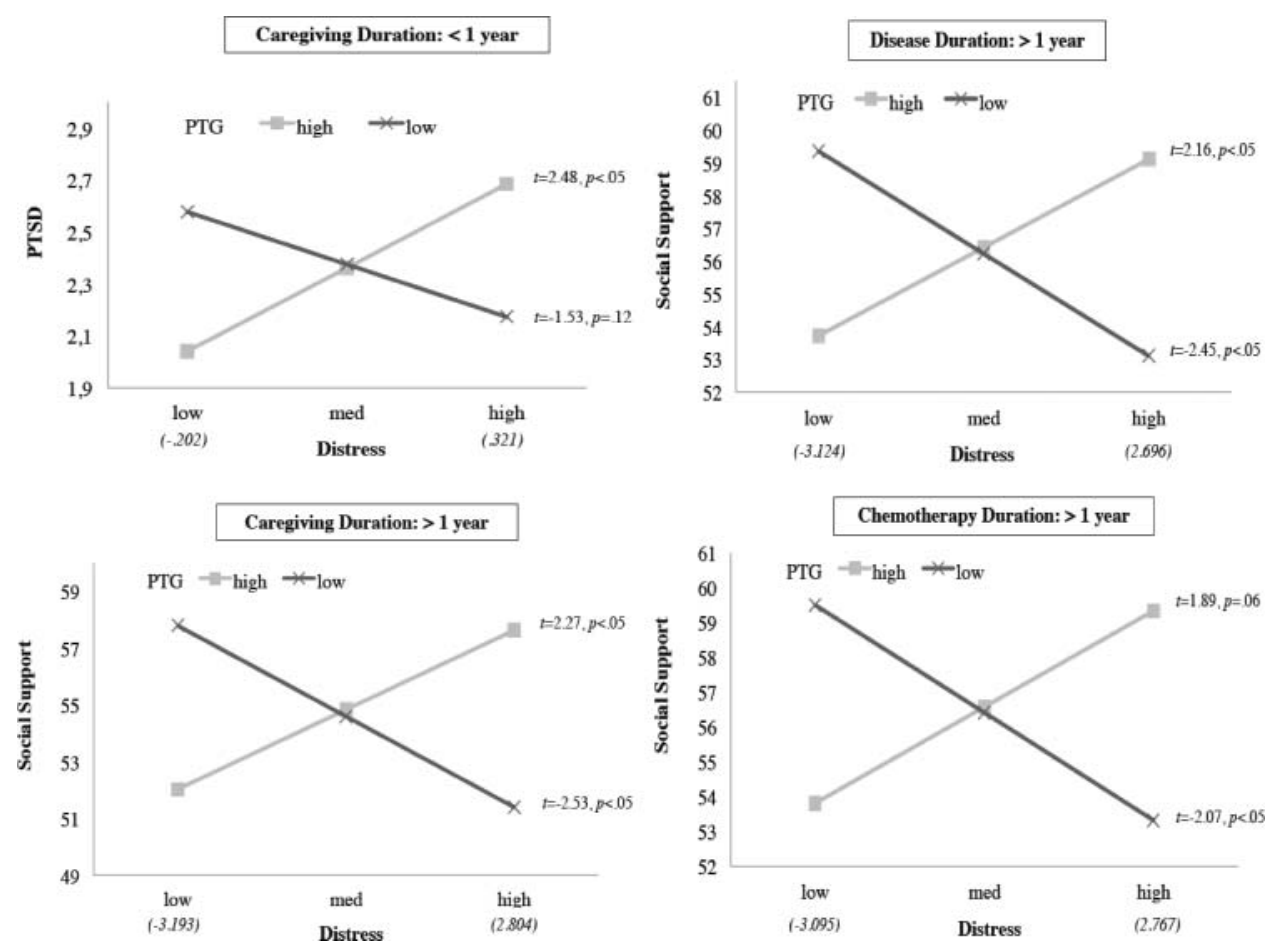

FIGURE 1 The moderating effects of posttraumatic growth (PTG) on the relationships between distress and posttraumatic stress disorder (PTSD)/social support. Depicted are unstandardized simple slopes for $1 \mathrm{SD}$ above and below the mean for PTG .

\section{DISCUSSION}

Although caregiving can potentiate physical, emotional, and financial burdens, it can also be rewarding. Some women caregivers reported a caregiver "gain," that is, more purpose in life than their noncaregiving women peers, as well as some beneficial effects including more autonomy, more personal growth, and more self-acceptance when caring for loved ones (Marks, Lambert, \& Choi, 2002). Even though there is a growing body of literature reporting on research examining the impact of parental cancer on young children and adolescents, there have been very few quantitative studies focused on the effects of parental cancer on adults (Kim, Schulz, \& Carver, 2007; Levesque \& Maybery, 2012; Mosher et al., 2006). This is a significant void, because many cancers typically occur in people older than age 50 (Levesque \& Maybery, 2012), and adult children feel a great deal of filial responsibility when faced with a sick parent (Logan \& Spitze, 1996).

This study shows that in a sample of adult children caregivers facing parental cancer, there are significant relationships between PTG and gender (Curbow et al., 1993; Linley \& Joseph, 2004; Park et al., 1996; Tedeschi 
\& Calhoun, 1996; Vishnevsky et al., 2010; Widows et al., 2005), level of dependency (Given et al., 1997; Nijboer et al., 1999; Teixeira \& Pereira, in press b), distress (Morris et al., 2005), PTSD symptoms (Zoellner \& Maercker, 2006), and aspects of family functioning (Uruk, Sayger, \& Cogdal, 2007). In turn, PTG was not significantly correlated with age, income, education, marital status, disease duration, chemotherapy duration, caregiving duration, social support, or family satisfaction.

Although it has not been shown that social support is correlated with PTG in this sample of adult children, it is believed to influence the development of PTG in many ways. Gender is one of them. Generally, research shows that women are more likely to report PTG than men solely because they appear to experience greater amounts of stress in response to adversity (Anderson \& Manuel, 1994; Rausch et al., 2008). This held true in this study, because PTGI women mean scores were statistically higher than men (as well as PTSD symptom severity). An association that might actually help to partly explain the relationship is related to the finding that individuals (especially females) who have experienced adverse events and received support from others tend to report feelings of closeness towards significant others (J. C. McMillen, 1999; S. Taylor et al., 2000). According to Swickert and Hittner's (2009), social support is not only associated with PTG, but also can function as a mediator in the relationship between gender and PTG. The authors believe the influence of social support is stronger in women because they naturally seek out others during times of stress (S. Taylor et al., 2000). Although this study sought to find whether this assumption could be supported in a sample of adult children caregivers, the results do not allow the confirmation of the first hypothesis, because in this sample social support does not function as a facilitator of PTG in women. This result can be interpreted in various ways. First, this outcome is not the result of a lack of reported social support, because the sample score is above the mean. Furthermore, although PTG requires some degree of distress, the stress does not need to coexist with satisfaction with social support. Actually, two major social strains that caregivers face are frequent social role changes (e.g., being a caregiver and a parent) and a decrease in social activities, which may lead to an increase in family conflict and have a negative impact on the couple's intimacy (Haley, 2003; Kim \& Given, 2008). This issue is very important because social support may not have an impact on helping informal caregivers find positive meanings. A more precise measure that looks specifically at social support and its association with PTG (Paul et al., 2010) may also be needed. Finally, as suggested by Linley and Joseph (2004), there might be a significant relationship between positive personal changes and satisfaction with social support, but not social support itself. This issue is fundamental because it seems to concern the type of social support that matters in the prediction of PTG (Schroevers et al., 2010).

The relationship between PTSD symptoms and PTG has proven to be complex (Zoellner \& Maercker, 2006). In this sample, a cutoff point in the 
measure of PTSD symptoms allowed the identification of 40\% possible PTSD cases, especially in the female subsample $(\mathrm{OR}=2.0)$. The cut off point for PTSD symptom's severity was useful in identifying cases of major PTG, because there were significant differences in overall PTG between PTSD and non-PTSD groups, especially at the level of relationships to others, and new possibilities. These results are congruent with previous reports about the prevalence of greater PTG in individuals facing parental cancer that suffer from higher levels of PTSD symptoms (Mosher \& Danoff-Burg, 2005). In support of the findings by Levine et al. (2008), the second hypothesis of this study was that a curvilinear relationship would be found when PTSD symptom severity was regressed against PTG. Overall, it was expected that the increased level of PTSD symptom severity will be positively related to the amount of PTG that adult children caregivers experience. However, the results showed only a significant linear effect of PTSD severity on growth and not a quadratic effect, which did not allow the confirmation of the hypothesis. This finding contrasts with previous research (Butler et al., 2005; Kleim \& Ehlers, 2009; Levine et al., 2008), and it may be the case that the length of time since the adverse event (conceptualized here as knowing the diagnosis of malignancy of the parent) and method of measurement contributed to the nonsignificant finding. Also, those with several different levels of PTSD symptom severity may experience higher levels of PTG. Further studies testing non-linear associations between PTG and PTSD are needed. However, the finding of significant curvilinear relationships is encouraging and suggests that researchers may be on the correct path to uncover the nature of the relationship.

Based on the existing literature, the third hypothesis proposed that sociodemographic, clinical, and psychosocial variables would predict PTG in the sample. Overall, this hypothesis was supported, as the model was significant and accounted for $22 \%$ of the variance. However, in accordance with existing literature on PTG, age (Bower et al., 2005; Cordova et al., 2007; Lechner et al., 2003; Mosher et al., 2006; Vishnevsky et al., 2010; Widows et al., 2005), income, and marital status (Devine, Reed-Knight, Loiselle, Fenton, \& Blount, 2010; Morrill et al., 2008; Mosher et al., 2006; Stanton, Bower, \& Low, 2006; Widows et al., 2005) did not emerge as significant predictors of increased PTG in adult children caregivers. The same results were found for the duration of treatment (Stanton et al., 2006), and caregiving duration (Mosher et al., 2006). With regard to psychosocial predictors of PTG, despite PTSD symptoms and social support been well supported in the scientific literature, using this sample and the regression model proposed, significant predictive effects did not emerge. This data does not contribute to the overall model of PTG (Tedeschi \& Calhoun, 1996; Tedeschi \& Calhoun, 2004), which indicates that social support is vital in the development of positive outcomes. However, empirical studies examining the relationship between PTG and social support yielded mixed findings. A positive relationship between social support and PTG has been found among husbands of women 
with breast cancer (T. Weiss, 2004a), bereaved HIV/AIDS caregivers (Cadell, Regehr, \& Hemsworth, 2003), and women living with HIV/AIDS (Siegel, Schrimshaw, \& Pretter, 2005), but a review of the literature suggests a weak relationship between these two variables (Linley \& Joseph, 2004), and some studies have found no relationship (Cordova et al., 2001). Higher PTSD symptoms were also nonsignificant predictors in the model. This finding is contrary to the expected model but is not inconsistent with the literature (Powell, Rosner, Butollo, Tedeschi, \& Calhoun, 2003). Several factors may have influenced this result. For example, elapsed time since the trauma has been suggested to affect the association (Milam, Ritt-Olson, \& Unger, 2004; Zoellner \& Maercker, 2006). Although PTG may be experienced relatively soon after a traumatic experience, the progression from trauma to growth takes considerable time. PTG may be experienced by those who continue to experience PTSD symptoms as well as by those whose distress has subsided.

In turn, there were some important significant predictors of PTG in this sample. One of the most well known is gender. Literature increasingly supports that women tend to report more PTG than men (Vishnevsky et al., 2010). Even though the causes of this relationship remain unclear (Curbow et al., 1993; Linley \& Joseph, 2004; Park et al., 1996; Tedeschi \& Calhoun, 1996; Vishnevsky et al., 2010; Widows et al., 2005), several assumptions have been made. One possible explanation could be that gender differences are in fact due to biological differences, whereas greater societal latitude for women to express their feelings might be another explanation (Anderson \& Manuel, 1994). Within family caregivers in cancer contexts, in fact women seem to use more emotion-focused coping (i.e., thinking about the event, trying to make sense of it, and trying to work through it cognitively) than men (Mosher et al., 2006; Wagner, Bigatti, \& Storniolo, 2006), which according to Tedeschi and Calhoun (2004) can actually promote greater PTG. Another significant sociodemographic predictor was education. Although education is generally unrelated to measures of personal growth in the literature (Fromm et al., 1996; Katz, Flasher, Cacciapaglia, \& Nelson, 2001; Lechner et al., 2003; Tempelaar et al., 1989), two reports found a relationship between more education and greater benefit finding (Morrill et al., 2008; Sears et al., 2003). On the contrary, however, being less well educated was a significant predictor of PTG in this study, a result that mirrors Widows et al.'s findings (2005), in a sample of cancer patients undergoing bone marrow transplantation. Longer disease duration was also a predictor associated with higher levels of PTG. One possible explanation for this result could be that during the first weeks or months after learning of a parent's potentially fatal illness, adult children have to adjust to the personal and familiar implications of this crisis, with the aggravation of having to provide direct care to the patient. Thus, caregivers may lack the time and psychological stability to consider any positive outcomes of their experience. This reaction pattern was relevant in samples of women with breast cancer (Cordova et al., 2001; Tomich \& Helgeson, 2002). 
Among other worries (e.g., disease recurrence or progression, as well as developing new cancers), cancer patients may have serious concerns about an increased risk for dependency (Mehnert, Berg, Henrich, \& Herschbach, 2009). But this concern is shared by family members, including the adult children. Considering this premise, this study assessed the subjective perceptions of adult children about the ill parents' level of dependency. As a predictor variable, this measure also emerged as significant in the regression model, showing that adult children who perceive their parents as more dependent on them and their care reported higher levels of PTG. These results are in accordance with the PTG model proposed by Calhoun and Tedeschi (2008), in which a strong stressor engagement, that is, the disease and the parent's degree of dependence, promotes a greater sense of PTG. Distress was also shown to be a significant positive predictor of PTG in the regression analysis. That is, with increased severity of distress symptoms, participants tended to report greater positive changes subsequent to their parental cancer experience. This finding somewhat supports Tedeschi and Calhoun's (1995, 2004) conceptual view of growth, because in their model of the PTG process, distress may be necessary for the development of growth; however, it was expected that PTSD symptoms would also contribute to the prediction, which did not happen. Evidence relating psychological distress to PTG has been limited and inconsistent (Cordova et al., 2001; Edmonds \& Hooker, 1992; Joseph, Williams, \& Yule, 1993; C. McMillen, Zuravin, \& Rideout, 1995; Sears et al., 2003), because a number of studies have shown an inverse relationship between these outcomes, such that greater perceived PTG is related to less distress (Frazier et al., 2001). There is also evidence for a positive relationship, in which greater PTG is related to more distress (Morris et al., 2005). Therefore, PTG and distress may not be opposite ends of a single dimension but rather may be distinct outcomes of trauma that are independent of each other. These results suggest that following traumatic experiences, adult children with parental cancer may report positive changes yet still suffer negative consequences, thus demonstrating that PTG and psychological distress can coexist (Grubaugh \& Resick, 2007; Lev-Wiesel, Amir, $\&$ Besser, 2005). Finally, the correlational analysis showed positive associations between PTG and several dimensions of family functioning (cohesion, flexibility, and communication). Interestingly, Uruk et al. (2007) report that "from the perspective of the Circumplex model, the significant relationships between psychological well-being and family functioning can be related to three important family functions (cohesion, adaptability, and communication) that can never be fully replaced by any other social structure" (p. 58). However, the authors decided to only include in the regression model the dimension of family functioning most highly correlated with PTG, which was family flexibility. Knowing that family flexibility has a significant influence on trauma symptoms and psychological well-being, that is, the relationship of family flexibility with trauma is negative (in this study they were not 
significantly related) whereas with psychological well-being this relationship is positive (Burt, Cohen, \& Bjorck, 1988; Rutledge, Davies, \& Davies, 1994; Shek, 1997), the present findings are consistent with previous literature showing that flexibility scores are linearly related to adjustment (Franko, Thompson, Bauserman, Affenito, \& Striegel-Moore, 2008; Gorbett \& Kruczek, 2008; Marsac \& Alderfer, 2011; Steinhausen, Haslimeier, \& Metzke, 2007). The current results indicate that higher scores on the balanced subscale of flexibility were related to higher PTG for adult children caregivers facing parental cancer. This positive predictive relationship between balanced flexibility and PTG may reflect the positive influence of overall healthy family functioning. Families who are able to shift roles and rules within the family system in a healthy way are likely to demonstrate a greater overall healthy functioning.

Considering previous research with cancer patients around a possible stress-buffering role of PTG (Helgeson et al., 2006; Morrill et al., 2008; Park, Chmielewski, \& Blank, 2010; Silva, Moreira, \& Canavarro, 2012), the last hypothesis of this study was that PTG has a moderating effect in the relationship between distress and other psychosocial variables (PTSD symptoms, and social support) in the adult children, with regard to the duration of different stressors related to parental cancer. As mentioned above, studies considering disease and/or treatment duration and PTG have yielded mixed outcomes. Although it is not clear that PTG occurs as more time elapses since the negative event (Prati \& Pietrantoni, 2009), it is a process that unfolds gradually over a period of time following accommodation to new trauma-related factors, because traumatic events generally require massive schematic changes (Joseph \& Linley, 2005).

The present results confirm that PTG (particularly when it is high) was a significant moderator of the linear positive relationship between distress and PTSD in adult children, with caregiving responsibilities that lasted less than one year. These data are consistent with previous studies reporting that most changes resulting from struggles with adversity occur between two weeks and 2 months posttrauma (Frazier et al., 2001), and that psychological distress and PTG can, actually, co-occur (Cadell et al., 2003; Calhoun \& Tedeschi, 2004; Salter \& Stallard, 2004; Zoellner \& Maercker, 2006). However, PTG was also a moderator in the relationship between distress and social support in adult children whose parents were diagnosed with cancer and received treatment for more than one year, implying a longer caregiving experience. The moderating effect was significant for higher levels of PTG, when the linear relationship between distress and social support is positive, meaning the processing of distress associated with parental cancer, in a perceived supportive social context, can be influenced by PTG (Mosher et al., 2006). Although, for lower levels of PTG, the linear relationship between distress and social support was negative and stronger. This result may represent that PTG can act as an important protective factor, because when it is low the relationship between social support and distress is negative. These findings contribute 
to the discussion about the nature of PTG as an outcome or a coping process (Tedeschi \& Calhoun, 2004). This discussion is important because the diagnosis and treatment of cancer involves considerable distress on patients' relatives, compromising their coping strategies (Teixeira \& Pereira, 2011). Even so, it can be stated that PTG certainly reflects a cognitive adaptation (Helgeson et al., 2006) in response to caregiving's demands of adult children of cancer patients because, according to Calhoun and Tedeschi (2008), care providers rely on different resources when faced with stressors associated with the disease, and a tendency for action may in fact contribute to PTG.

Some limitations of this study must be acknowledged. The crosssectional design limits the ability to infer causal relationships among the variables, the exclusive use of self-report measures and the fact that type of tumor and tumor stage have not been controlled for. Future research may benefit from exploring individual differences such as perceptions of global meaning, coping strategies, and optimism, which previous research has demonstrated to be associated with PTG (Rini et al., 2004; Vickberg, Bovbjerg, DuHamel, Currie, \& Redd, 2000). Like other studies, only one family member per cancer survivor was included in this study. Each family member or close friend experiences different levels and types of stress from the cancer of their loved one and has different coping resources available (Kim et al., 2007). Studying one family member cannot comprehensively evaluate the impact of cancer on a particular family. Current findings should be replicated in future studies that include multiple family members as well as the cancer survivor. Future research could also benefit by interviewing adult children facing parental cancer right after diagnosis and beginning of treatment following them over time, taking into account previous qualitative data with samples of adolescents (Kissil, Niño, Jacobs, Davey, \& Tubbs, 2010; Oktay, 2005) and adult children of cancer patients (Kissil et al., 2010; Levesque \& Maybery, 2012; Oktay, 2005; Puterman \& Cadell, 2008; W. K. Wong, Ussher, \& Perz, 2009).

This study has some implications for clinical practice. For example, for younger adult children, parental cancer could represent less access to social support, which can promote a potential isolation. Targeted support groups and/or individual counseling for these adult children can be beneficial. These interventions could be of great importance in helping adult children maintain or refrain hope, as well as enduring the uncertainty of the future. For adult children caregivers that are married, with children and job responsibilities, also known as "sandwich generation" (Rubin \& WhiteMeans, 2009), these interventions could be targeted to stress management. They can also be focused on identifying positive outcomes and meaning in their experiences (Given \& Sherwood, 2006). Concerning gender differences, it is well established that women are more likely to seek professional help than men (Pederson \& Vogel, 2007). In cancer caregiving's contexts this reality is certainly similar, so mental health professionals have a greater 
probability of treating women with PTG. However, it should not be overlooked that men caregivers seeking help may have more difficulties in reporting PTG. So they should be encouraged to engage in self-disclosure (Vishnevsky et al., 2010) to elaborate on the difficult experiences associated with caregiving, and to explore the ways in which they may have changed. Finally, the results from this study could also lead to interventions designed to increase the experience of PTG in this specific population (Stanton et al., 2006), which may be especially relevant to distress and PTSD symptoms (through a buffering effect), not only during caregiving but also following bereavement.

\section{REFERENCES}

Aiken, L. S., \& West, S. G. (1991). Multiple regression: Testing and interpreting interactions. Newbury Park, CA: Sage.

Anderson, K. M., \& Manuel, G. (1994). Gender differences in reported stress response to the Loma Prieta earthquake. Sex Roles, 30(9/10), 725-733.

Andrykowski, M. A., Brady, M., \& Hunt, J. (1993). Positive psychosocial adjustment in potential bone marrow transplant recipients: Cancer as a psychosocial transition. Psycho-Oncology, 2(4), 261-276.

Baider, L. A., \& De-Nour, A. K. (1988). Breast cancer - A family affair. In C. L. Cooper (Ed.), Stress and breast cancer (pp. 155-170). New York, NY: John Wiley \& Sons.

Barakat, L. P., Alderfer, M. A., \& Kazak, A. E. (2006). Posttraumatic growth in adolescent survivors of cancer and their mothers and fathers. Journal of Pediatric Psychology, 31(4), 413-419.

Barakat, L. P., \& Kazak, A. E. (1999). Family issues. In R. T. Brown (Ed.), Cognitive aspects of chronic illness in children (pp. 333-354). New York, NY: Guilford Press.

Barnes, H. L., \& Olson, D. H. (1985). Parent-adolescent communication and the Circumplex Model. Special issue: Family development. Child Development, 56(2), 438-447.

Baron, R. M., \& Kenny, D. A. (1986). The moderator-mediator variable distinction in social psychological research: Conceptual, strategic and statistical considerations. Journal of Personality and Social Psychology, 51(6), 1173-1182.

Bellizzi, K. M., \& Blank, T. A. (2006). Predicting posttraumatic growth in breast cancer survivors. Health Psychology, 25(1), 47-56.

Bower, J. E., Meyerowitz, B. E., Desmond, K. A., Bernaards, C. A., Rowland, J. H., \& Ganz, P. A. (2005). Perceptions of positive meaning and vulnerability following breast cancer: Predictors and outcomes among long-term breast cancer survivors. Annals of Behavioral Medicine, 29(3), 236-245.

Burt, C. E., Cohen, L. H., \& Bjorck, J. P. (1988). Perceived family environment as a moderator of young adolescents' life stress adjustment. American Journal of Community Psychology, 16(1), 101-122.

Butler, L. D., Blasey, C. M., Garlan, R. W., McCaslin, S. E., Azarow, J., Chen, X., ... Spiegel, D. (2005). Posttraumatic growth following the terrorist attacks of 
September 11, 2001: Cognitive, coping, and trauma symptom predictors in an Internet convenience sample. Traumatology, 11(4), 247-267.

Cadell, S., Regehr, C., \& Hemsworth, D. (2003). Factors contributing to posttraumatic growth: A proposed structural equation model. American Journal of Orthopsychiatry, 73(3), 279-287.

Calhoun, L. G., \& Tedeschi, R. G. (1998). Posttraumatic growth: Future directions. In R. G. Tedeschi, C. L. Park, \& L. G. Calhoun (Eds.), Posttraumatic growth: Positive changes in the aftermath of crisis (pp. 215-238). Mahwah, NJ: Lawrence Erlbaum Associates.

Calhoun, L. G., \& Tedeschi, R. G. (1999). Facilitating posttraumatic growth: A clinician's guide. Mahwah, NJ: Lawrence Erlbaum Associates.

Calhoun, L. G., \& Tedeschi, R. G. (2004). The foundations of posttraumatic growth: New considerations. Prychological Inquiry, 15, 93-102.

Calhoun, L. G., \& Tedeschi, R. G. (2008). The paradox of struggling with trauma: Guidelines for practice and directions for research. In S. Joseph \& P. A. Linley (Eds.), Trauma, recovery, and growth: Positive psychological perspectives on posttraumatic stress (pp. 325-337). Hoboken, NJ: John Wiley \& Sons.

Carver, C. S., \& Antoni, M. H. (2004). Finding benefit in breast cancer during the year after diagnosis predicts better adjustment 5 to 8 years after diagnosis. Health Psychology, 23(6), 595-598.

Chun, S., \& Lee, Y. (2008). The experience of posttraumatic growth for people with spinal cord injury. Qualitative Health Research, 18(7), 877-890.

Collins, R. L., Taylor, S. E., \& Skokan, L. A. (1990). A better world or a shattered vision? Changes in life perspectives following victimization. Social Cognition, $8(3), 263-285$.

Cordova, M. J. (2008). Facilitating posttraumatic growth following cancer. In S. Joseph \& P. A. Linley (Eds.), Trauma, recovery, and growth: Positive Psychological perspectives on posttraumatic stress (pp. 185-205). Hoboken, NJ: John Wiley \& Sons.

Cordova, M. J., Cunningham, L. L., Carlson, C. R., \& Andrykowski, M. A. (2001). Posttraumatic growth following breast cancer: A controlled comparison study. Health Psychology, 20(3), 176-185.

Cordova, M. J., Giese-Davis, J., Golant, M., Kronenwetter, C., Vickie, C., \& Spiegel, D. (2007). Breast cancer as trauma: Posttraumatic stress and posttraumatic growth. Journal of Clinical Psychology in Medical Settings, 14(4), 308-319.

Coyne, J., Benazon, N., Gaba, C. G., Calzone, K., \& Weber, B. L. (2000). Distress and psychiatric morbidity among women from high-risk breast and ovarian cancer families. Journal of Consulting and Clinical Psychology, 68(5), 864-874.

Creamer, M., Bell, R., \& Failla, S. (2003). Psychometric properties of the Impact of Event Scale-Revised. Behaviour Research and Therapy, 41(12), 1489-1496.

Curbow, B., Legro, M. W., Baker, F., Wingard, J. R., \& Somerfield, M. R. (1993). Loss and recovery themes of long-term survivors of bone marrow transplants. Journal of Psychosocial Oncology, 10(4), 1-20.

Curran, P. J., Bauer, D. J., \& Willoughby, M. T. (2004). Testing main effects and interactions in latent curve analysis. Psychological Methods, 9(2), 220-237. 
Davis, C. G., Nolen-Hoeksema, S., \& Larson, J. (1998). Making sense of loss and benefiting from the experience: Two construals of meaning. Journal of Personality and Social Psychology, 75(2), 561-574.

Davis, C. G., Wohl, M. J., \& Verberg, N. (2007). Profiles of posttraumatic growth following an unjust loss. Death Studies, 31(8), 693-712.

Devine, K. A., Reed-Knight, B., Loiselle, K. A., Fenton, N., \& Blount, R. L. (2010). Posttraumatic growth in young adults who experienced serious childhood illness: A mixed-methods approach. Journal of Clinical Psychology in Medical Settings, 17(4), 340-348.

Edmonds, S., \& Hooker, K. (1992). Perceived changes in life meaning following bereavement. Omega: Journal of Death and Dying, 25(4), 307-318.

Fontana, A., \& Rosenheck, R. (1998). Psychological benefits and liabilities of traumatic exposure in the war zone. Journal of Traumatic Stress, 11(3), 485-505.

Franko, D., Thompson, D., Bauserman, R., Affenito, S., \& Striegel-Moore, R. (2008). What's love got to do with it? Family cohesion and healthy eating behaviors in adolescent girls. International Journal of Eating Disorders, 41(4), 360-367.

Frazier, P., Conlon, A., \& Glaser, T. (2001). Positive and negative life changes following sexual assault. Journal of Consulting and Clinical Psychology, 69(6), 1048-1055.

Fromm, K., Andrykowski, M. A., \& Hunt, J. (1996). Positive and negative psychosocial sequelae of bone marrow transplantation: Implications for quality of life assessment. Journal of Behavioral Medicine, 19(3), 221-240.

Gallagher, J., Parle, M., \& Cairns, D. (2002). Appraisal and psychological distress six months after diagnosis of breast cancer. British Journal of Health Psychology, 7(Part 3), 365-376.

Given, B., \& Sherwood, P. R. (2006). Family care for the older person with cancer. Seminars in Oncology Nursing, 22(1), 43-50.

Given, B. A., Given, C. W., Helms, E., Stommel, M., \& DeVoss, D. N. (1997). Determinants of family care giver reaction. New and recurrent cancer. Cancer Practice, 5(1), 17-24.

Given, B. A., Stommel, M., Given, C. W., Osuch, J., Kurtz, M. E., \& Kurtz, J. C. (1993). The influence of cancer patient symptoms functional states on patient depression and family caregiver reaction and depression. Health Psychology, 12(4), 277-285.

Gorbett, K., \& Kruczek, T. (2008). Family factors predicting social self-esteem in young adults. The Family Journal, 16(1), 58-65.

Grubaugh, A. L., \& Resick, P. A. (2007). Posttraumatic growth in treatment-seeking female assault victims. Psychiatric Quarterly, 78(2), 145-155.

Haley, W. E. (2003). The costs of family caregiving: Implications for geriatric oncology. Critical Reviews in Oncology-Hematology, 48(2), 151-158.

Hawley, D. R., \& DeHaan, L. (1996). Toward a definition of family resilience: Integrating life-span and family perspectives. Family Process, 35(3), 283-298.

Helgeson, V. S., Reynolds, K. A., \& Tomich, P. L. (2006). A meta-analytic review of benefit finding and growth. Journal of Consulting \& Clinical Psychology, 74(5), 797-816. 
Joseph, S., \& Linley, P. A. (2005). Positive adjustment to threatening events: An organismic valuing theory of growth through adversity. Review of General Psychology, 9(3), 262-280.

Joseph, S., Williams, R., \& Yule, W. (1993). Changes in outlook following disaster: The preliminary development of a measure to assess positive and negative responses. Journal of Traumatic Stress, 6(2), 271-279.

Kash, K. M., Holland, J. C., Halper, M. S., \& Miller, D. G. (1992). Psychological distress and surveillance behaviors of women with a family history of breast cancer. Journal of National Cancer Institute, 84(1), 24-30.

Katz, R. C., Flasher, L., Cacciapaglia, H., \& Nelson, S. (2001). The psychosocial impact of cancer and lupus: A cross validation study that extends the generality of "benefit finding" in patients with chronic disease. Journal of Behavioral Medicine, 24(6), 561-571.

Kim, Y., Duberstein, P. R., Sörensen, S., \& Larson, M. R. (2005). Levels of depressive symptoms in spouses of people with lung cancer: Effects of personality, social support, and caregiving burden. Psychosomatics, 46(2), 123-130.

Kim, Y., \& Given, B. A. (2008). Quality of life of family caregivers of cancer survivors. Cancer, 112(S11), 2556-2568.

Kim, Y., Schulz, R., \& Carver, C. S. (2007). Benefit finding in the cancer caregiving experience. Psychosomatic Medicine, 69(3), 283-291.

Kim, Y., Wellisch, D. K., Spiller, R. L., \& Crammer, C. (2007). Psychological distress of female cancer caregivers: Effects of type of cancer and caregivers' spirituality. Supportive Care in Cancer, 15(12), 1367-1374.

Kissil, K., Niño, A., Jacobs, S., Davey, M., \& Tubbs, C. Y. (2010). "It has been a good growing experience for me": Growth experiences among African American youth coping with parental cancer. Families, Systems, E Health, 28(3), 274-289.

Klauer, T., Ferring, D., \& Filipp, S. H. (1998). "Still stable after all this ... ?": Temporal comparisons in coping with severe and chronic disease. International Journal of Behavioral Development, 22(2), 339-355.

Kleim, B., \& Ehlers, A. (2009). Evidence for a curvilinear relationship between posttraumatic growth and posttrauma depression and PTSD in assault survivors. Journal of Traumatic Stress, 22(1), 45-52.

Kornblith, A. B., Anderson, J., Cella, D. F., Tross, S., Zuckerman, E., Cherin, E., ... Silver, R. T. (1990). Quality of life assessment of Hodgkin's disease survivors: A model for cooperative clinical trials. Oncology, 4(5), 93-101.

Lechner, S. C., Zakowski, S. G., Antoni, M. H., Greenhawt, M., Block, K., \& Block, P. (2003). Do sociodemographic and disease-related variables influence benefitfinding in cancer patients? Psycho-Oncology, 12(5), 491-499.

Leedham, B., \& Meyerowitz, B. E. (1999). Responses to parental cancer: A clinical perspective. Journal of Clinical Psychology in Medical Settings, 6(4), 441-461.

Lev-Wiesel, R., Amir, M., \& Besser, A. (2005). Posttraumatic growth among female survivors of childhood sexual abuse in relation to the perpetrator identity. Journal of Loss and Trauma, 10(1), 7-17.

Levesque, J. V., \& Maybery, D. (2012). Parental cancer: Catalyst for positive growth and change. Qualitative Health Research, 22(3), 397-408. 
Levine, S. Z., Laufer, A., Hamama-Raz, Y., Stein, E., \& Solomon, Z. (2008). Posttraumatic growth in adolescence: Examining its components and relationship with PTSD. Journal of Traumatic Stress, 21(5), 492-496.

Linley, P. A., \& Joseph, S. (2004). Positive change following trauma and adversity: A review. Journal of Traumatic Stress, 17(1), 11-21.

Linley, P. A., Joseph, S., \& Goodfellow, B. (2008). Positive changes in outlook following trauma and their relationship to subsequent posttraumatic stress, depression, and anxiety. Journal of Social and Clinical Psychology, 27(8), 877-891.

Logan, J. R., \& Spitze, G. D. (1996). Family ties: Enduring relations between parents and their grown children. Philadelphia, PA: Temple University Press.

Lovibond, P., \& Lovibond, S. (1995). The structure of negative emotional states: comparison of the Depression Anxiety Stress Scales (DASS) with the Beck Depression and Anxiety Inventories. Behaviour Research and Therapy, 33(3), 335-343.

Manne, S., Ostroff, J., Winkel, G., Goldstein, L., Fox, K., \& Grana, G. (2004). Posttraumatic growth after breath cancer: patient, partner and couple perspectives. Psychosomatic Medicine, 66(3), 442-454.

Marks, N., Lambert, J. D., \& Choi, H. (2002). Transitions to caregiving, gender, and psychological well-being: A prospective U.S. national study. Journal of Marriage and Family, 64(3), 657-667.

Marsac, M. L., \& Alderfer, M. A. (2011). Psychometric properties of the FACES-IV in families of pediatric oncology patients. Journal of Pediatric Psychology, 36(5), 528-538.

Massie, M., \& Holland, J. C. (1990). Overview of normal reactions and prevalence of psychiatric disorder. In J. C. Holland \& J. H. Rowland (Eds.), Handbook of psycho-oncology (pp. 273-278). New York, NY: Oxford University Press.

McMillen, C., Zuravin, S., \& Rideout, G. (1995). Perceived benefit from child sexual abuse. Journal of Consulting \& Clinical Psychology, 63(6), 1037-1043.

McMillen, J. C. (1999). Better for it: How people benefit from adversity. Social Work, 44(5), 455-468.

McMillen, J. C., Smith, E. M., \& Fisher, R. H. (1997). Perceived benefit and mental health after three types of disaster. Journal of Consulting \& Clinical Psychology, 65(5), 733-739.

Mehnert, A., Berg, P., Henrich, G., \& Herschbach, P. (2009). Fear of cancer progression and cancer-related cognitions in breast cancer survivors. Psycho-Oncology, 18(12), 1273-1280.

Milam, J. E., Ritt-Olson, A., \& Unger, J. B. (2004). Posttraumatic growth among adolescents. Journal of Adolescent Research, 19(2), 192-204.

Moore, A. M., Gamblin, T. C., Geller, D. A., Youssef, M. N., Hoffman, K. E., Gemmell, L., ... Steel, J. L. (2010). A prospective study of posttraumatic growth as assessed by self-report and family caregiver in the context of advanced cancer. PsychoOncology, 20(5), 479-487.

Morrill, E. F., Brewer, N. T., O'Neill, S. C., Lillie, S. E., Dees, E. C., Carey, L. A., \& Rimer, B. K. (2008). The interaction of posttraumatic growth and posttraumatic stress symptoms in predicting depressive symptoms and quality of life. PsychoOncology, 17(9), 948-953. 
Morris, B. A., Shakespeare-Finch, J., Rieck, M., \& Newbery, J. (2005). Multidimensional nature of posttraumatic growth in an Australian population. Journal of Traumatic Stress, 18(5), 575-585.

Mosher, C. E., \& Danoff-Burg, S. (2005). Psychosocial impact of parental cancer in adulthood: A conceptual and empirical review. Clinical Psychology Review, 25(3), 365-382.

Mosher, C. E., Danoff-Burg, S., \& Brunker, B. (2006). Post-traumatic growth and psychosocial adjustment of daughters of breast cancer survivors. Oncology Nursing Forum, 33(3), 543-551.

Moyer, A., \& Salovey, P. (1996). Psychosocial sequelae of breast cancer and its treatment. Annals of Behavioral Medicine, 18(2), 110-125.

Nijboer, C., Triemstra, M., Tempelaar, R., Sanderman, R., \& van den Bos, G. A. (1999). Determinants of caregiving experiences and mental health of partners of cancer patients. Cancer, 86(4), 577-588.

Offit, K., \& Brown, K. (1994). Quantitating familial cancer risk: A resource for clinical oncologists. Journal of Clinical Oncology, 12(8), 1724-1736.

Oktay, J. S. (2005). Breast cancer: Daughters tell their stories. New York, NY: Haworth Press.

Olson, D. H. (2004). Family Satisfaction Scale (FSS). Minneapolis, MN: Life Innovations.

Olson, D. H. (2011). FACES IV \& the circumplex model: Validation study. Journal of Marital E Family Therapy, 3(1), 64-80.

Olson, D. H., \& Barnes, H. (2004). Family communication. Minneapolis, MN: Life Innovations.

Olson, D. H., Gorall, D. M., \& Tiesel, J. W. (2006a). FACES IV. Development and validation. Minneapolis, MN: Life Innovations.

Olson, D. H., Gorall, D. M., \& Tiesel, J. W. (2006b). FACES-IV package: Administration. Minneapolis, MN: Life Innovations.

Pais-Ribeiro, J. L. (1999). Escala de Satisfação com o Suporte Social (ESSS) [Satisfaction with Social Support Scale (SSSS)]. Análise Psicológica, 17(3), 547-558.

Pais-Ribeiro, J. L., Honrado, A., \& Leal, I. (2004). Contribuição para o estudo da adaptação portuguesa das escalas de ansiedade, depressão e stress (EADS) de 21 itens de Lovibond e Lovibond [Contribution to the study of Portuguese adaptation of the 21 items depression, anxiety and stress scales (DASS) of Lovibond and Lovibond]. Psicologia, Saúde E Doenças, 5(2), 229-239.

Park, C. L., Chmielewski, J., \& Blank, T. O. (2010). Post-traumatic growth: finding positive meaning in cancer survivorship moderates the impact of intrusive thoughts on adjustment in younger adults. Psycho-Oncology, 19(11), 1139-1147.

Park, C. L., Cohen, L. H., \& Murch, R. L. (1996). Assessment and prediction of stress-related growth. Journal of Personality, 64(1), 71-105.

Patterson, J. M. (2002). Integrating family resilience and family stress theory. Journal of Marriage and the Family, 64(2), 349-361.

Paul, M. S., Berger, R., Berlow, N., Rovner-Ferguson, H., Figlerski, L., Gardner, S., \& Malave, A. F. (2010). Posttraumatic growth and social support in individuals with infertility. Human Reproduction, 25(1), 133-141. 
Pederson, E. L., \& Vogel, D. L. (2007). Male gender role conflict and willingness to seek counseling: Testing a mediation model of college-aged men. Journal of Counseling Psychology, 54(4), 373-384.

Pereira, M. G., \& Teixeira, R. J. (2011). Portuguese validation of the Impact of Event Scale-Revised (IES-R) in adult children of cancer patients. PsychoOncology, 20(Suppl 2), 146. Retrieved from http://onlinelibrary.wiley.com/ doi/10.1002/pon.2078/abstract

Pereira, M. G., \& Teixeira, R. J. (in press). Portuguese validation of the FACES-IV in a sample of adult children caregivers. Contemporary Family Therapy.

Powell, S., Rosner, R., Butollo, W., Tedeschi, R. G., \& Calhoun, L. G. (2003). Posttraumatic growth after war: A study with former refugees and displaced people in Sarajevo. Journal of Traumatic Stress, 59(1), 71-83.

Prati, G., \& Pietrantoni, L. (2009). Optimism, social support, and coping strategies as factors contributing to posttraumatic growth: A meta-analysis. Journal of Loss and Trauma, 14(5), 364-388.

Preacher, K. J., Rucker, D. D., \& Hayes, A. F. (2007). Addressing moderated mediation hypotheses: Theory, methods, and prescriptions. Multivariate Behavioral Research, 42(1), 185-227.

Puterman, J., \& Cadell, S. (2008). Timing is everything: the experience of parental cancer for young adult daughters-A pilot study. Journal of Psychosocial Oncology, 26(2), 103-121.

Rausch, S. M., Auerbach, S. M., \& Gramling, S. E. (2008). Gender and ethnic differences in stress reduction, reactivity, and recovery. Sex Roles 59(9/10), $726-737$.

Rini, C., Manne, S., DuHamel, K. N., Austin, J., Ostroff, J., Boulad, F., ... Redd, W. H. (2004). Mothers' perceptions of benefit following pediatric stem cell transplantation: A longitudinal investigation of the roles of optimism, medical risk, and sociodemographic resources. Annals of Behavioral Medicine, 28(2), 132-141.

Rubin, R. M., \& White-Means, S. I. (2009). Informal caregiving: Dilemmas of sandwiched caregivers. Journal of Family and Economic Issues, 30(3), 252-267.

Russell, C. S., White, M. B., \& White, C. P. (2006). Why me? Why now? Why multiple sclerosis?: Making meaning and perceived quality of life in a Midwestern sample of patients with multiple sclerosis. Families, Systems, \& Health, 24(1), 65-81.

Rutledge, C. M., Davies, S. M., \& Davies, T. C. (1994). Family dysfunction and the well-being of medical students. Family Systems Medicine, 12(2), 197-204.

Salter, E., \& Stallard, P. (2004). Posttraumatic growth in child survivors of a road traffic accident. Journal of Traumatic Stress, 17(4), 335-340.

Santos, C. S., Pais-Ribeiro, J. L., \& Lopes, C. (2003). Estudo da adaptação da escala de satisfação com o suporte social (ESSS) a pessoas com diagnóstico de doença oncológica [Adaptation study of the Satisfaction with Social Support Scale (SSSS) to people with a diagnosis of cancer]. Psicologia Saúde E Doenças, 4(2), 185-204

Schnurr, P. P., Rosenberg, S. D., \& Friedman, M. J. (1993). Change in MMPI scores from college to adulthood as a function of military service. Journal of Abnormal Psychology, 102(2), 288-296.

Schroevers, M. J., Helgeson, V. S., Sanderman, R., \& Ranchor, A. V. (2010). Type of social support matters for prediction of posttraumatic growth among cancer survivors. Psycho-Oncology, 19(1), 46-53. 
Schulz, U., \& Mohamed, N. E. (2004). Turning the tide: Benefit finding after cancer surgery. Social Science \& Medicine, 59(3), 653-662.

Schumacher, K. L. (1996). Reconceptualizing family caregiving: Family-based illness care during chemotherapy. Research in Nursing \& Health, 19(4), 261-271.

Sears, S. R., Stanton, A. L., \& Danoff-Burg, S. (2003). The yellow brick road and the emerald city: Benefit-finding, positive reappraisal coping, and posttraumatic growth in women with early stage breast cancer. Health Psychology, 22(5), 487-497.

Shakespeare-Finch, J. E., Smith, S. G., Gow, K. M., Embleton, G., \& Baird, L. (2003). The prevalence of posttraumatic growth in emergency ambulance personnel. Traumatology, 9(1), 58-70.

Shek, D. T. (1997). Family environment and adolescent psychological well-being, school adjustment and problem behavior: A pioneer study in a Chinese context. Journal of Genetic Psychology, 158(1), 113-128.

Siegel, K., Schrimshaw, E. W., \& Pretter, S. (2005). Stress-related growth among women living with HIV/AIDS: Examination of an explanatory model. Journal of Behavioral Medicine, 28(5), 403-414.

Silva, S. M., Moreira, H. C., \& Canavarro, M. C. (2012). Examining the links between perceived impact of breast cancer and psychosocial adjustment: The buffering role of posttraumatic growth. Psycho-Oncology, 21(4), 409-418.

Stanton, A. L., Bower, J. E., \& Low, C. A. (2006). Posttraumatic growth after cancer. In L. G. Calhoun \& R. G. Tedeschi (Eds.), Handbook of posttraumatic growth: research and practice (pp. 138-175). Mahwah, NJ: Erlbaum.

Steinhausen, H., Haslimeier, C., \& Metzke, C. W. (2007). Psychosocial factors in adolescent and young adult self-reported depressive symptoms: Causal or correlational associations? Journal of Youth and Adolescence, 36(1), 89-100.

Swickert, R., \& Hittner, J. (2009). Social support coping mediates the relationship between gender and posttraumatic growth. Journal of Health Psychology, 14(3), 387-393.

Taku, K., Cann, A., Calhoun, L. G., \& Tedeschi, R. G. (2008). The factor structure of the Posttraumatic Growth Inventory: A comparison of five models using confirmatory factor analysis. Journal of Traumatic Stress, 21(2), 156-164.

Tamres, L., Janicki, D., \& Helgeson, V. S. (2002). Sex differences in coping behavior: A meta-analytic review. Personality and Social Psychology Review, 6(1), 2-30.

Taylor, E. J. (2000). Transformation of tragedy among women surviving breast cancer. Oncology Nursing Forum, 27(5), 781-788.

Taylor, S., Klein, L., Lewis, B., Gruenwald, T., Gurung, R., \& Updegraff, J. (2000). Biobehavioral responses to stress in females: Tend-and-befriend, not flight-orfight. Psychological Review, 107(3), 411-429.

Tedeschi, R. G., \& Calhoun, L. G. (1995). Trauma and transformation: Growing in the aftermath of suffering. Thousand Oaks, CA: Sage.

Tedeschi, R. G., \& Calhoun, L. G. (1996). The posttraumatic growth inventory: Measuring the positive legacy of trauma. Journal of Traumatic Stress, 9(3), 455-472.

Tedeschi, R. G., \& Calhoun, L. G. (2004). Posttraumatic growth: Conceptual foundations and empirical evidence. Psychological Inquiry, 15(1), 1-18.

Teixeira, R. J., \& Pereira, M. G. (2011). Impacto do câncer parental no desenvolvimento psicológico dos filhos: Uma revisão da literatura [Impact of parental 
cancer in offspring's psychological development: Literature review]. Psicologia: Reflexão e Crítica, 24(3), 513-522.

Teixeira, R. J., \& Pereira, M. G. (in press a). Growth and the cancer caregiving experience: Psychometric properties of the Portuguese Posttraumatic Growth Inventory. Families, Systems, \& Health.

Teixeira, R. J., \& Pereira, M. G. (in press b). Psychological morbidity, burden and the mediating effect of social support in adult children caregivers of oncological patients undergoing chemotherapy. Psycho-Oncology.

Tempelaar, R., de Haes, J. C., de Ruiter, J. H., Bakker, D., van den Heuvel, W. J., \& van Nieuwenhuijzen, M. G. (1989). The social experiences of cancer patients under treatment: A comparative study. Social Science and Medicine, 29(5), 635-642.

Thewes, B., Meiser, B., Tucker, K., \& Schnieden, V. (2003). Screening for psychological distress and vulnerability factors in women at increased risk for breast cancer: A review of the literature. Psychology, Health \& Medicine, 8(3), 289-303.

Thornton, A. A., \& Perez, M. A. (2006). Posttraumatic growth in prostate cancer survivors and their partners. Psycho-Oncology, 15(4), 285-296.

Tomich, P. L., \& Helgeson, V. S. (2002). Five years later: A cross-sectional comparison of breast cancer survivors with healthy women. Psycho-Oncology, 11(2), 154-169.

Toseland, R., Blanchard, C., \& McCallion, P. (1995). A problem solving intervention for caregivers of cancer patients. Social Science and Medicine, 40(4), 517528.

Updegraff, J. A., Taylor, S. E., Kemeny, M. E., \& Wyatt, G. E. (2002). Positive and negative effects of HIV infection in women with low socioeconomic resources. Personality and Social Psychology Bulletin, 28(3), 382-394

Uruk, A. C., Sayger, T. V., \& Cogdal, P. A. (2007). Examining the influence of family cohesion and adaptability on trauma symptoms and psychological well-being. Journal of College Student Psychotherapy 22(2), 51-63.

Vickberg, S. M., Bovbjerg, D. H., DuHamel, K. N., Currie, V., \& Redd, W. H. (2000). Intrusive thoughts and psychological distress among breast cancer survivors: Global meaning as a possible protective factor. Behavioral Medicine, 25(4), 152-160.

Vishnevsky, T., Cann, A., Calhoun, L. G., Tedeschi, R. G., \& Demakis, G. J. (2010). Gender differences in self-reported posttraumatic growth: A meta-analysis. Psychology of Women Quarterly, 34(1), 110-120.

Wagner, C. D., Bigatti, S. M., \& Storniolo, A. M. (2006). Quality of life of husbands of women with breast cancer. Psycho-Oncology, 15(2), 109-120.

Walsh, F. (2003). Family resilience: A framework for clinical practice. Family Process, 42(1), 1-18.

Wang, L., Zhang, J., Shi, Z., Zhou, M., Huang, D., \& Liu, P. (2011). Confirmatory factor analysis of posttraumatic stress symptoms assessed by the Impact of Event Scale-Revised in Chinese earthquake victims: Examining factor structure and its stability across sex. Journal of Anxiety Disorders, 25(3), 369-375.

Warren, K., Franklin, C., \& Streeter, C. L. (1998). New directions in systems theory: Chaos and complexity. Social Work, 43(4), 357-372. 
Weiss, D., \& Marmar, C. (1997). The Impact of Event Scale-Revised. In J. P. Wilson \& T. M. Keane (Eds.), Assessing psychological trauma and PTSD: A practitioner's handbook (pp. 399-411). New York, NY: Guilford Press.

Weiss, T. (2002). Posttraumatic growth in women with breast cancer and their husbands: An intersubjective validation study. Journal of Psychosocial Oncology, 20(2), 65-80.

Weiss, T. (2004a). Correlates of posttraumatic growth in husbands of breast cancer survivors. Psycho-Oncology, 13(4), 260-268.

Weiss, T. (2004b). Correlates of posttraumatic growth in married breast cancer survivors. Journal of Social and Clinical Psychology, 23(5), 733-746.

Wells, J. N., Cagle, C. S., Bradley, P., \& Barnes, D. M. (2008). Voices of Mexican American caregivers for family members with cancer: On becoming stronger. Journal of Transcultural Nursing, 19(3), 223-233.

Widows, M. R., Jacobsen, P. B., Booth-Jones, M., \& Fields, K. K. (2005). Predictors of posttraumatic growth following bone marrow transplantation for cancer. Health Psychology, 24(3), 266-273.

Wolchik, S. A., Coxe, S., Tein, J. Y., Sandler, I. N., \& Ayers, T. S. (2008). Sixyear longitudinal predictors of posttraumatic growth in parentally bereaved adolescents and young adults. Omega, 58(2), 107-128.

Wong, M. L., Cavanaugh, C. E., Macleamy, J. B., Sojourner-Nelson, A., \& Koopman, C. (2009). Posttraumatic growth and adverse long-term effects of parental cancer in children. Families, Systems, \& Health, 27(1), 53-63.

Wong, W. K., Ussher, J., \& Perz, J. (2009). Strength through adversity: Bereaved cancer carers' accounts of rewards and personal growth from caring. Palliative and Supportive Care, 7(2), 187-196.

Zoellner, T., \& Maercker, A. (2006). Posttraumatic growth in clinical psychology: A critical review and introduction of a two component model. Clinical Psychology Review, 26(5), 626-653.

Zwahlen, D., Hagenbuch, N., Carley, M. I., Jenewein, J., \& Buchi, S. (2010). Posttraumatic growth in cancer patients and partners-Effects of role, gender and the dyad on couples' posttraumatic growth experience. Psycho-Oncology, 19(1), $12-20$. 